\title{
Worldwide comparison of the levels of anxiety and depression during the COVID-19 pandemic
}

\section{Comparación mundial de los niveles de ansiedad y depresión durante la pandemia de COVID-19}

\author{
Calsin Atencio-Janela, Francis Aranguren-Avendaño and Oriana Rivera-Lozada* \\ Universidad Privada San Juan Bautista, Escuela Profesional de Medicina Humana. Chorrillos, Lima, Peru
}

We have read the article "Symptoms of anxiety, depression, and self-care behaviors during the COVID-19 pandemic in the general population," published in Gaceta Médica de México volume 156, number 4, about a survey carried out in 1507 people, in $27.5 \%$ of whom symptoms of severe depression were identified, and in $20.8 \%$, symptoms of severe anxiety ${ }^{1}$. In China, in a study carried out by the Peking University, depression was identified in $27.9 \%$ out of 56,932 people, with a minimal difference of $0.4 \%$ with regard to the proportion referred in the article published by Gaceta, and $31.6 \%$ of anxiety, with a large difference of $10.8 \%{ }^{2}$. Similarly, in the Kingdom of Saudi Arabia, a survey was conducted in 1160 subjects of the general population; a similar percentage of depression was obtained: $28.3 \%$, with a difference of $0.8 \%$, as well as of anxiety, $24 \%$, with a difference of $3.2 \%{ }^{3}$.

In the study published in Gaceta Médica de México, the levels of depression were similar to those recorded in China and the Kingdom of Saudi Arabia because confirmed or suspected cases of COVID-19 and people at risk of occupational exposure were identified. In conclusion, the different generalized intervention measures are currently considered a major public health problem (including the quarantine, delays in returning to daily activities, and changes in the labor sphere), which have affected both the countries of Latin America and the Asian continent and have been associated with negative results that have caused mental health complications in the world.

\section{References}

1. Galindo-Vázquez O, Ramírez-Orozco M, Costas-Muñiz R, Mendoza-Contreras LA, Calderillo-Ruiz G, Meneses-García A. Síntomas de ansiedad, depresión y conductas de autocuidado durante la pandemia de COVID-19 en la población general. Gac Med Mex. 2020;156:298-305.

2. Shi L, Lu ZA, Que JY, Huang XL, Liu L, Ran MS, et al. Prevalence of risk factors associated with mental health symptoms among the general population in China during the Coronavirus disease 2019 pandemic. JAMA Netw Open. 2020:3:e2014053.

3. Alkhamees A, Alrashed SA, Alzunaydi AA, Almohimeed AS, Aljohani MS. The psychological impact of COVID-19 pandemic on the general population of Saudi Arabia. Compr Psychiatry. 2020;102:152192. 